\title{
特別寄稿
}

\section{Treatment Strategy for Grade III Arteriovenous Malformations}

\author{
Mattos JP, M. D. ${ }^{* * *}$, Ghizoni E, M. D. ${ }^{* *}$, de Oliveira E, Ph. D. *,**, and Tedeschi H, Ph. D. ${ }^{* *}$ \\ *Institute of Neurological Sciences (ICNE) and \\ ** Department of Neurosurgery, Campinas State University (UNICAMP)
}

The treatment of arteriovenous malformation(AVMs) depends on the efforts of a multidisciplinary team to provide better results than its natural course. Treatment options are reviewed based on our personal experience series of 208 grade III operated AVMs in a 10-year period. The Spetzler-Martin classification was modified to include subdivisions in the heterogeneous group of grade III AVMs as follows: IIIA (large cortical AVMs), IIIB (small limbic lobe AVMs) and IIIC (small insula lobe AVMs), to augment the surgical resection criteria. The treatment strategy was for most of the cases embolization plus surgery for grade IIIA, surgery for subdivision IIIB and radiosurgery for most and surgery for selected cases of IIIC. The surgical results (good outcome: IIIA $81 \%$, IIIB $86 \%$ and IIIC $87 \%$ ) showed that in spite of the higher surgical and anatomical complexity for the IIIC group in comparison with those IIIB and IIIA AVMs, there are selected cases that can be surgically approached with similar or even better surgical outcomes based on the subdivision proposed. Indeed, these data indicate that the treatment of AVMs can achieve better results when compared to its natural course if managed by a well-trained group of specialists led by an experienced neurosurgeon.

(Received October 27, 2004; accepted November 16, 2004) Key words : arteriovenous malformation, brain vascular malformation, intracranial hemorrhage,
grade III AVM, surgical treatment of AVM

Jpn J Neurosurg（Tokyo） 14:363-367, 2005

\section{Introduction}

The management of arteriovenous malformation is one of the most difficult problems in neurosurgery. There are many decisive factors regarding the choice of therapeutic modalities. An experienced team composed of a neuroradiologist, endovascular neuroradiologist, radiosurgeon and an experienced vascular neurosurgeon are basic requisites to achieve an acceptable result. A multidisciplinary decision is the best way to offer better results with less morbidity for the patients.

Even when all of the treatment options are available, many neurologists and neurosurgeons refer their patients to a single modality of treatment and do not consider prescribing them to a whole therapeutic plan. Treatment should only be indicated after a complete evaluation considering such factors as occupation, age, clinical status of the patient, confrontation among the results of all therapeutic modalities and it must always be considered whether the risk of the treatment offered will surpass the risk of leaving the disease untreated. In such cases, the best option must be to leave the lesion untreated.

Endovascular embolization plays an important role as an adjuvant therapy to the microsurgical resection of large lesions and for subsequent radiosurgery. Even in the best hands, the rate of cure alone is still very low.

Radiosurgery is the treatment modality that can be used to achieve cure in a great number of those patients presenting small lesions, however, one of the disadvantages of this kind of therapy is the long time required for

Address for correspondence: Prof. de Oliveira E, Ph. D., Instituto de Ciências Neurológicas, Praça Amadeu Amaral, 27-5 andar-CEP 01320-010 São Paulo, SP, Brasil 
Table 1 AVM Spetzler-Martin classification

\begin{tabular}{llr}
\hline Features & score \\
\hline Size & Small $(<3 \mathrm{~cm})$ & 1 \\
& Medium $(3 \sim 6 \mathrm{~cm})$ & 2 \\
Eloquent area & Large $(>6 \mathrm{~cm})$ & 3 \\
& No & 0 \\
Venous drainage & Yes & 1 \\
& Superficial & 0 \\
& Deep & 1 \\
\hline
\end{tabular}
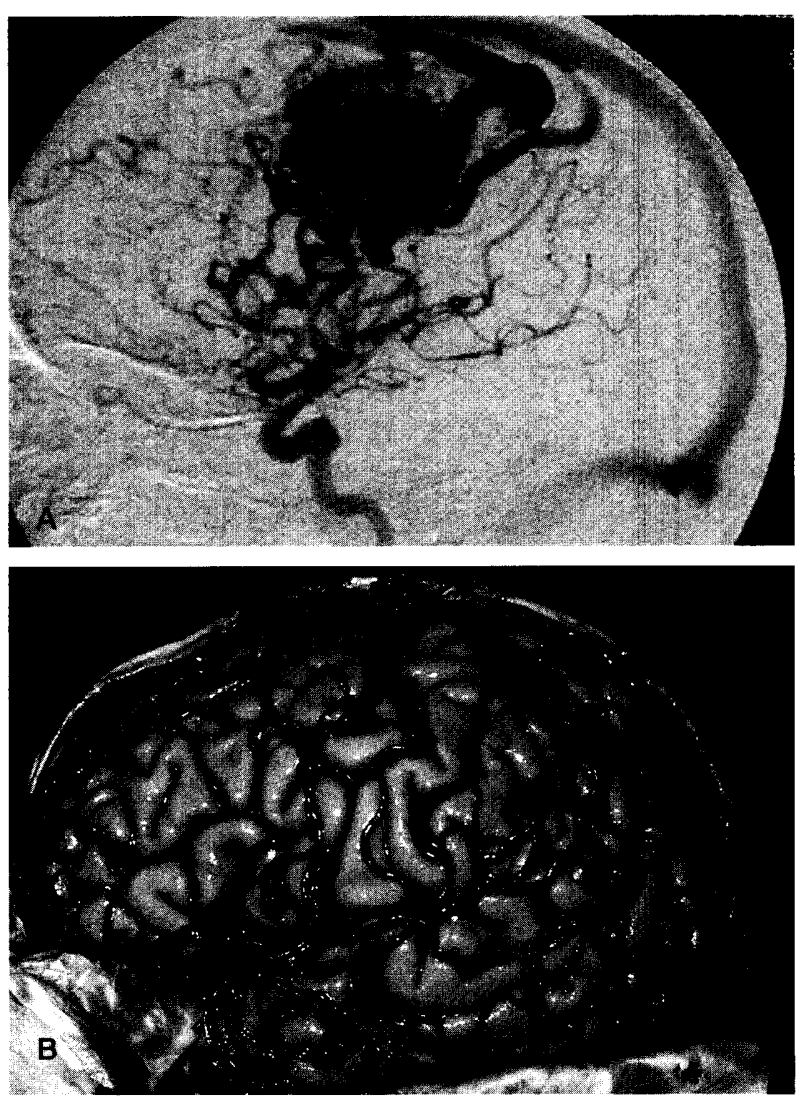

Fig. 1 A : Grade IIIA AVM. Left carotid angiogram showing a medium superficial AVM located in an eloquent area.

B : Anatomical specimen showing the vascular pattern of superficial drainage and the arterial supply usually found in this kind of lesion of the central sulcus area. Note that the AVM usually follows the normal vascular pattern.

complete obliteration of the AVMs (around 2-3 years) with the patients remaining unprotected from hemorrhagic events during this period of time.

The challenge of AVM surgery is such that even at this time only a few neurosurgeons are adequately prepared to deal with this pathology. Poor initial arteriovenous malformation surgical results have led to a conservative attitude towards AVMs leading neurologists and neurosurgeons to initially refer those patients to adjuvant treatment modalities. This led to insufficient training programs regarding AVMs for young neurosurgeons and few numbers of cases being referred to more experienced neurosurgeons.

With the development of microsurgical techniques, advances in neuroimaging, neuroanesthesia, operative monitoring and post-operative intensive care, the surgical treatment became possible.

Considering that grade III Spetzler-Martin AVMs are some of the most difficult lesions for deciding which type of therapeutic plan should be carried out and that they comprise a heterogeneous group that has different surgical difficulties and therapeutic indications, the authors suggest a three staged subdivision of grade III Spetzler-Martin AVMs. The division into three subgroups will allow the indication for adequate treatment for each case easier to assess and will make each group more uniform, allowing the group results to be compared more often.

All treatment modalities have advantages and disadvantages. This shows that the best therapy must be decided after multidisciplinary discussion between an endovascular and a radiosurgeon led by a neurosurgeon, at which time, the best strategy individualized for each patient can be dtermined.

\section{Classification}

In order to decide whether or not to operate on supratentorial AVMs and to determine the necessity of adjuvant treatment we use the widely accepted grading system proposed by Spetzler and Martin ${ }^{1)}$ (Table 1). This classification takes into consideration the size, venous drainage and localization of the AVM and gives some idea about the surgical risks and difficulties involved in the surgical resection of the lesions. The simplicity and facility to apply the Spetzler-Martin classification is another advantage of this grading system.

However, the classification can be misleading in some cases. As an example, a medium frontal AVM localized in an eloquent area, like a central sulcus AVM, is grade III as is a small thalamic AVM protruding in the floor of the lateral ventricle. Indeed, a small medial cingulate AVM with deep venous drainage is classified as grade III also. 
Although these lesions are all grade III in the Spetzler-Martin grading system, the difficulty and risks involved in surgery for those examples are completely different. Likewise, a $5 \mathrm{~cm}$ central sulcus or occipital pole AVM has a higher risk to lead to deficits than a $2 \mathrm{~cm}$ AVM located at the uncus.

Since AVMs in the same group offer different difficulties for surgery with different surgical prognosis and different indications to be treated, many subgroups can be created.

For this reason, and in order to the better understand and treat grade III lesions, we have subdivided the Spetzler-Martin classification into three subgroups: IIIA, IIIB and IIIC. Grade IIIA AVMs are considered those medium AVMs in an eloquent area or non-eloquent lesions bigger than $6 \mathrm{~cm}$ with superficial venous drainage, in spite of the last being rarely found. Grade IIIB are those small AVMs located at the limbic lobe and corpus callosum with deep venous drainage. Grade IIIC are usually those small deep-seated AVMs with deep venous drainage and commonly supplied by perforating arteries, located at the insula lobe (with these limits : anterior, anterior isthmus; posterior, posterior isthmus ; medial, the head of the caudate nucleus and thalamus from anterior to posterior; lateral, by the insula cortex; superior and inferior, by the superior and inferior limitating insular sulcus, respectively).

\section{Grade III A}

AVMs classified in this group are lesions that are considered grade III that are superficial medium sized, located at eloquent areas or the uncommon non eloquent large cortical AVMs, as these are usually in contact to eloquent areas or have deep venous drainage meaning that they are most often considered grade IV AVMs. Also, deep medium sized AVMs without deep venous drainage are extremely rare, so lesions classified in the subgroup IIIA are usually in the lateral hemispheric surface (Fig. 1). Considering that the surgery for these AVMs is often difficult, prior embolization is usually required to facilitate the surgical procedure or if it is the patient's option. Therefore, unless the clinical conditions prove to be a limitating factor, we manage Grade IIIA patients with pre-operative embolization followed by microsurgical resection. Alternatively, radiosurgery after embolization can be performed if there
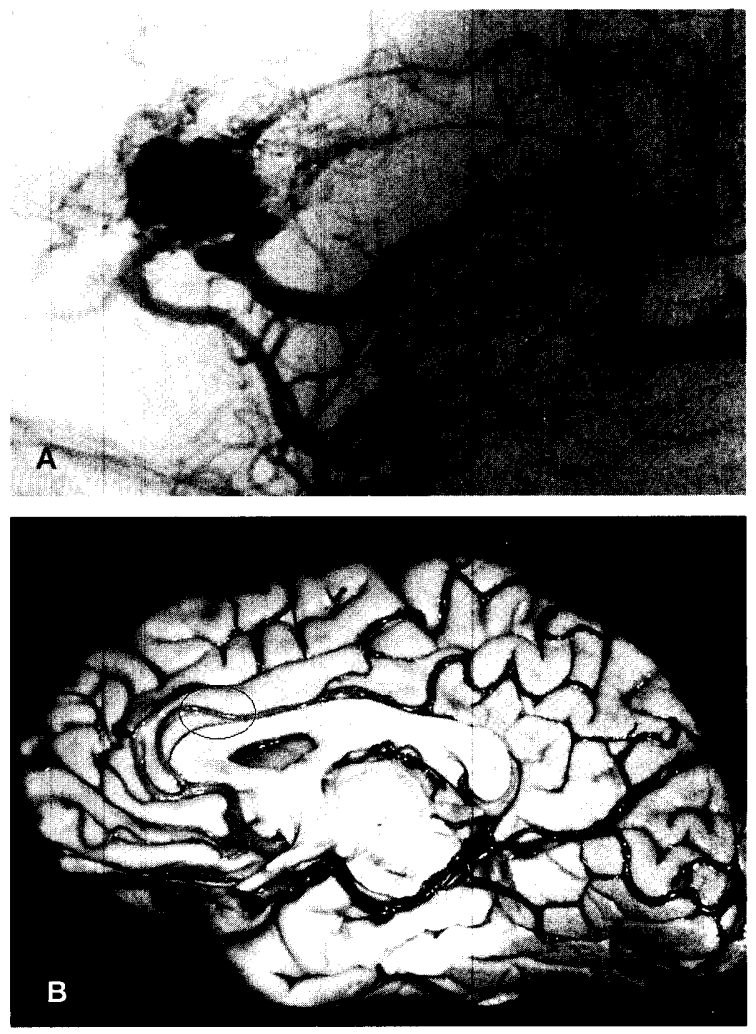

Fig. 2 A : Grade IIIB AVM. A right side digital carotid angiogram showing a small AVM located at the cingulated gyrus and corpus callosum. It is supplied predominantly by branches from the anterior cerebral artery and with deep venous drainage.

B : Medial aspect of the right cerebral hemisphere showing the anatomy of the region where the presented arteriovenous malformation is located. These lesions are located at the superficial aspect of the medial side of the limbic lobe, at the cisternal spaces. The circular mark shows the topography of the lesion visualized in Fig. 2A.

is no indication for surgical treatment.

\section{Grade III B}

These AVMs are those smaller than $3 \mathrm{~cm}$ in size and usually localized in the mesial aspect of the temporal lobe, therefore with deep venous drainage and situated in an eloquent area. These specific AVMs has an increased surgical facility compared with deep seated lesions as the former are in the cisterns providing a natural corridor to approach these lesions with less morbidity and allowing the surgeon to work in an anatomical space (Fig. 2). These cases are treated by surgery or radiosurgery. These are the limbic lobe, corpus callosum, paraolfatory gyrus and paraterminal gyrus AVMs. 

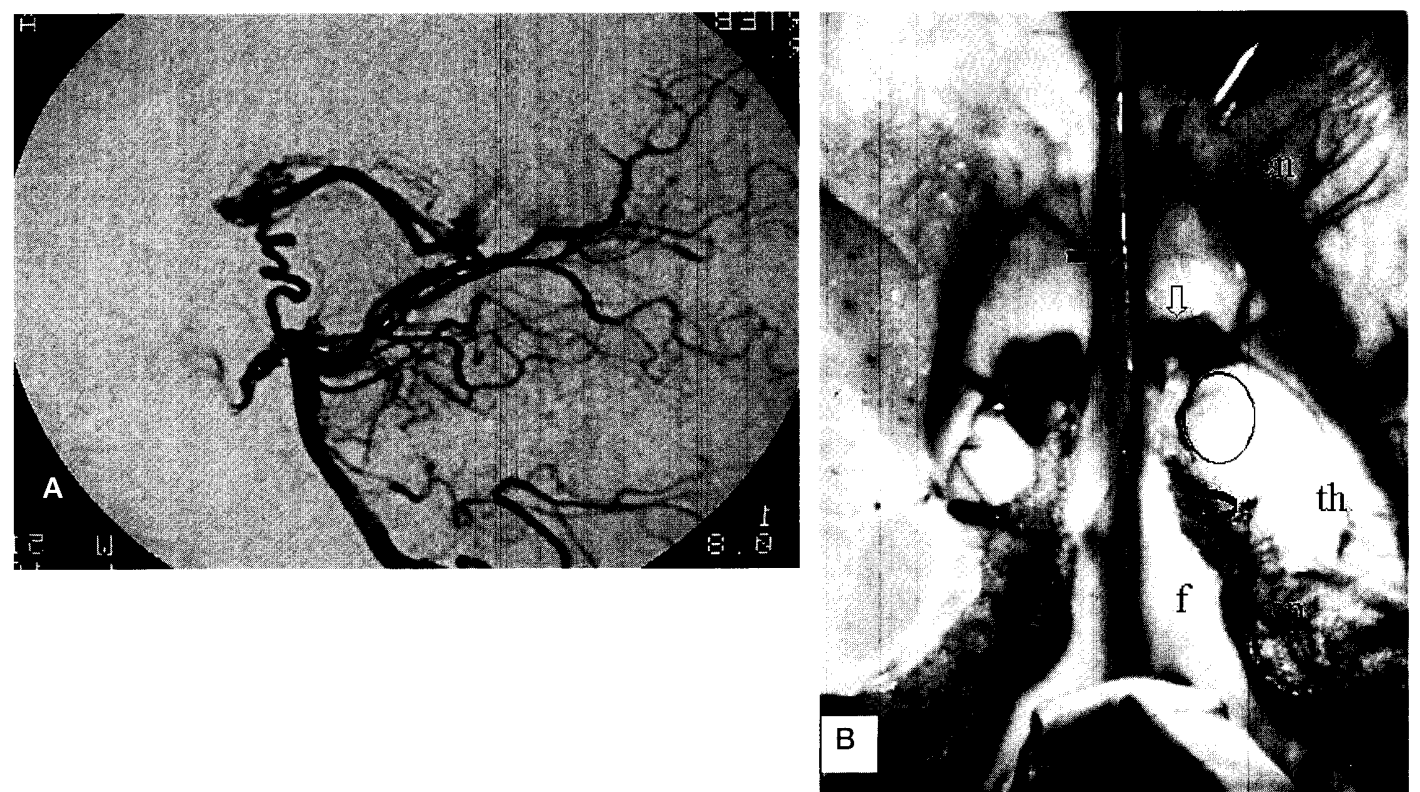

Fig. 3 A : Grade IIIC AVM. A vertebral angiogram showing a small anterior thalamic AVM supplied predominantly by posterior thalamoperforating arteries with deep venous drainage to the internal cerebral veins.

B : An anatomical specimen showing that the lateral part of the floor of the body of the lateral ventricle is composed of the superior part of thalamus where this lesion is superficially located as demonstrated by the circular mark. During surgery, after opening the corpus callosum, such a lesion becomes visible allowing its surgical resection with minimal risk of morbidity. It is an example of a grade IIIC lesion where the surgical approach can be done with acceptable results. $\mathrm{f}:$ fornix; th : thalamus; $\mathrm{cp}$ : choroid plexus; $\mathrm{cn}:$ caudate nucleus; arrow : right foramen of Monro; black arrow: septum pellucidum; curve arrow: choroidal fissure between fornix and choroid plexus.

\section{Grade III C}

AVMs classified in this subgroup are small lesions usually located in the insula lobe, therefore eloquent and with deep venous drainage and often with feeders from the lenticulostriate arteries or perforating vessels from the carotid, posterior cerebral, posterior communicating, anterior choroidal and anterior medial choroidal arteries. Surgery is either too difficult or prohibitive. The treatment of choice is radiosurgery.

However, even this subgroup is not completely uniform and there are many exceptions to this rule. Some deep seated lesions, especially those located in some areas of the insula lobe, usually less than $2 \mathrm{~cm}$, sparing the central area of this central core, internal capsule and lenticular nucleus; as those AVMs restricted to the head of the caudate nucleus, pulvinar of the thalamus, lateral ventricular thalamic floor or those restricted outside the lenticular nucleus, at the claustrum or insular cortex, can be surgically excised (Fig. 3) with minimal morbidity with similar or better results than with IIIA and IIIB lesions (Table 2).
Table 2 Surgical results of grade III AVMs

\begin{tabular}{cccccc}
\hline Grade & $\begin{array}{c}\text { No of } \\
\text { cases }\end{array}$ & $\begin{array}{c}\text { Good } \\
\text { outcome }\end{array}$ & $\begin{array}{c}\text { Fair } \\
\text { outcome }\end{array}$ & $\begin{array}{c}\text { Bad } \\
\text { outcome }\end{array}$ & Death \\
\hline IIIA & 48 & 39 & 5 & 3 & 1 \\
& $(23 \%)$ & $(81.3 \%)$ & $(10 \%)$ & $(6 \%)$ & $(2 \%)$ \\
IIIB & 104 & 90 & 12 & 1 & 1 \\
& $(50 \%)$ & $(86.5 \%)$ & $(11.5 \%)$ & $(1 \%)$ & $(1 \%)$ \\
IIIC & 56 & 49 & 6 & 0 & 1 \\
& $(27 \%)$ & $(87.5 \%)$ & $(11 \%)$ & & $(2 \%)$ \\
\hline Total & 208 & 178 & 23 & 4 & 3 \\
& $(100 \%)$ & $(85.6 \%)$ & $(11.1 \%)$ & $(1.9 \%)$ & $(1.4 \%)$ \\
\hline
\end{tabular}

Table 3 Treatment algorithm for grade III AVMs

\begin{tabular}{cll}
\hline Grade & \multicolumn{1}{c}{ Treatment } & \multicolumn{1}{c}{ Option } \\
\hline IIIA & Embolization + & Embolization + \\
& Surgery & Radiosurgery \\
IIIB & Surgery & Radiosurgery \\
IIIC & Radiosurgery & Surgery \\
\hline
\end{tabular}


The treatment algorithm for grade III AVMs is shown in Table 3.

Bad results include patients that become hemiplegic or aphasic. Fair results are those who developed neurological deficit but kept a Karnofsky status of 70 or more. Good results refer to patients without neurological deficits.

In our series, the grade IIIC AVMs bleed more often and the patients had a poor neurological status as compared with the former groups.

\section{Conclusion}

The best treatment of AVMs should be decided by a team working cooperatively and composed of an endovascular neuroradiologist and a radiosurgeon and led by a specially trained neurosurgeon. Each case is studied by all of them together and the best therapeutic decision is then selected for each case.

The idea of a multidisciplinary team also includes neuroanesthesists, intensive care physicians, neurologists, neuropsychologists, nurses and a dedicated contingent of professionals prepared to manage the patients with this complex pathology.

The neurosurgeon must search for a detailed anatomical knowledge of the 3D view of the brain and its relations with neighboring structures. A refined microsurgical technique achieved after a long learning period in a laboratory training program is mandatory.

Fianally, the surgical treatment must offer the patient a better chance than the natural course of the AVM.

\section{References}

1) Spetzler RF, Martin NA : A proposed grading system for arteriovenous malformation. J Neurosurg $65: 476-483,1986$.

\section{脳神経外科ジャーナル}

\section{総 説}

胎児期における中枢神経系画像診断 ·香川小児病院 夫 律子, 他 脊髄髄膜瘤に係る諸問題 千葉県こども病院 伊達 裕昭, 他 小児の水頭症に対する第三脳室底開空術とその問題点 順天堂大学 宮嶋 雅一, 他

重症頭部外傷の病態と治療 久留米大学 徳 富 孝 志

\section{原 著}

進行性水頭症による神経伝達機構の機能損傷 :

サーキットとしてのドーパミン作働性黒質一線条体神経路の変化………市立舞鶴市民病院 田代 弦, 他 手術手技 ・周術期管理

Multimodality を用いた petroclival meningioma の治療 山形大学 嘉山 孝正, 他 症例報告

脳室腹腔シャント機能不全に伴う一過性の akinetic mutism

編集の都合上内容が若干異なる場合がありますのでご了承ください． 